\title{
Overgrowth and trisomy 15q26.1-qter including the IGF1 receptor gene: report of two families and review of the literature
}

\author{
Laurence Faivre $^{1,4}$, Philippe Gosset ${ }^{1,4}$, Valérie Cormier-Daire ${ }^{1}$, Sylvie Odent ${ }^{2}$, Jeanne Amiel ${ }^{1}$, \\ Irina Giurgea ${ }^{1}$, Marie-Cécile Nassogne ${ }^{3}$, Laurent Pasquier ${ }^{2}$, Arnold Munnich ${ }^{1}$, \\ Serge Romana ${ }^{1}$, Marguerite Prieur ${ }^{1}$, Michel Vekemans ${ }^{1}$, Marie-Christine de Blois ${ }^{1}$ and \\ Catherine Turleau*,1
}

${ }^{1}$ Département de Génétique, Hôpital Necker-Enfants Malades, Paris, France; ${ }^{2}$ Service de Génétique, Hôpital Pontchaillou, Rennes, France; ${ }^{3}$ Service de Métabolisme et Neurologie Pédiatrique, Hôpital Necker-Enfants Malades, Paris, France

Overgrowth is rarely associated with chromosomal imbalances. Here we report on four children from two unrelated families presenting with overgrowth and a terminal duplication of the long arm of chromosome 15 diagnosed using cytogenetic and FISH studies. In both cases, chromosome analysis of the parents showed a balanced translocation involving 15q26.1-qter. Molecular and cytogenetic studies showed three copies of the insulin-like growth factor 1 receptor (IGF1R) gene. This finding suggests that overgrowth observed in our patients might be causally related to a dosage effect of the IGF1R gene, in contrast to severe growth retardation observed in patients with terminal deletion of $15 \mathrm{q}$. The present observation emphasises the importance of chromosome analysis in patients with overgrowth and mental retardation. Moreover, it further delineates a specific phenotype related to trisomy $15 q 26.1$-qter with macrosomia at birth, overgrowth, macrocephaly and mild developmental delay being the major clinical features.

European Journal of Human Genetics (2002) 10, 699- 706. doi:10.1038/sj.ejhg.5200879

Keywords: overgrowth; macrocephaly; trisomy 15q26.1-qter; insulin-like growth factor 1 receptor gene

\section{Introduction}

Although overgrowth is observed in several genetic syndromes, its molecular basis is unravelled only in a small number of them including Beckwith-Wiedemann syndrome, ${ }^{1}$ Simpson-Golabi-Behmel syndrome ${ }^{2}$ and more recently Sotos syndrome. ${ }^{3}$ Overgrowth is rarely associated with chromosome imbalances. Presumably, a detailed study of these unusual cases can give us a clue for candidate chromosome regions or genes involved in the pathogenesis of overgrowth. Four partial trisomies including growth-related genes have been seen in overgrowth syndromes, including

*Correspondence: C Turleau; Service de Cytogénétique, Hôpital Necker Enfants Malades, 149, rue de Sèvres, 75015 Paris, France.

Tel: +33.1.44.49.49.82; Fax: +33.1.44.49.04.17; E-mail: turleau@necker.fr ${ }^{4}$ The first two authors contributed equally in this work

Received 14 March 2002; revised 3 July 2002; accepted 24 July 2002 trisomy 4p16.3 and the FGFR3 gene, ${ }^{4}$ trisomy $11 \mathrm{p} 15.5$ and the IGF2 gene, ${ }^{5}$ trisomy 20 p11.2 and the SSTR4 gene ${ }^{6}$ and trisomy 15 q25-qter. ${ }^{7}$ Overgrowth has been reported as well in association with tetrasomy 15 q25-qter. ${ }^{8}$ Observations of distal deletions of chromosome $15 q$ including the IGF1R gene suggest that growth failure might be related to IGF1R hemizygosity. ${ }^{9}$ Here we report on four patients with overgrowth and trisomy 15q26.1-qter including the IGF1R gene.

\section{Clinical reports}

Family 1

At least four patients were affected in family 1 (Figure 1a). Individual IV-5 was referred to us for genetic counselling because her daughter (V-4) and her niece (V-1) presented with mild developmental delay and macrocephaly. She 
had a sister and three brothers, two of which (IV-3 and IV6) had mild mental retardation with IQ between 50 and 70 , slight dysmorphism including an elongated face and macrocephaly. Their height was reported to be between 1.75 and $1.80 \mathrm{~m}$. Their karyotypes were initially considered as normal and fragile $\mathrm{X}$ syndrome was excluded. New clinical evaluation was denied.

Her daughter (V-4) was born at term after an uneventful pregnancy. At birth, length was $51 \mathrm{~cm}(+1 \mathrm{SD})$, weight was $4000 \mathrm{~g}$ (+2 SD) and occipito-frontal circumference (OFC) was $37 \mathrm{~cm}(+2 \mathrm{SD})$. Developmental delay was noted at 10 months, she began to walk at 20 months and was able to speak at 4 years. At $7 \frac{1}{2}$ years, her height was $1.25 \mathrm{~m}(+1$ SD), weight was $29 \mathrm{~kg}(+2 \mathrm{SD})$ and $\mathrm{OFC}$ was $57.2 \mathrm{~cm}(+4$ SD). She interacted well with her environment but had learning difficulties. She was mildly dysmorphic with a large head and frontal bossing, an elongated face, slight midface retraction, a pointed chin, and small low-set ears. Wrists and ankles were large and thumbs were short. Cardiac examination, renal ultrasound and neuroimaging were normal. Ophthalmologic examination showed a visual acuity of $5 / 10$ bilaterally.

Her niece (V-1) was born at term after an uneventful pregnancy. At birth, length was $53 \mathrm{~cm} \mathrm{(+3} \mathrm{SD),} \mathrm{weight}$ was $3300 \mathrm{~g}$ (mean) and OFC $36 \mathrm{~cm} \mathrm{(+1} \mathrm{SD).} \mathrm{Hypotonia}$ was noticed in the first month of life. She was admitted at 4 months of life for progressive overgrowth with macrocephaly. She sat at age $8 \frac{1}{2}$ months, walked at age 2 years, and presented speech delay. At 6 years of age, her height was $127 \mathrm{~cm}(+3.5 \mathrm{SD})$, weight was $23 \mathrm{~kg}(+2 \mathrm{SD})$ and OFC was $57 \mathrm{~cm}(+4 \mathrm{SD})$. Dysmorphic features included a long triangular face, high, large and flat forehead, downslanting palpebral fissures, slight enophtalmia, small round and low set ears, and a large chin (Figure 2a). Hyperlaxity of fingers were noted, with long and slender hands and proximal implantation of the thumbs. There was a moderate psycho- motor delay. Ophthalmologic and cardiac examination, neuroimaging and endocrine studies including growth hormone and $17 \mathrm{OH}$ progesterone were normal. Diagnosis of Sotos syndrome was initially proposed. Her father's occipito-frontal circumference was $60 \mathrm{~cm}$.

\section{Family 2}

Both siblings of family 2 were affected (Figure 1b). The parents originated from Antilles. The height and occipitofrontal circumference were respectively 163 and $57.5 \mathrm{~cm}$ in the mother and 190 and $58 \mathrm{~cm}$ in the father. The family history on the mother's side was unremarkable. The father had one half-sister, one half-brother and one brother. All of them presented with tall stature. The half-brother had developmental delay.

The pregnancy of the older sibling was uneventful and the baby was born at 38 weeks of gestation (WG). At birth, length was $49 \mathrm{~cm}$ (mean), weight $3590 \mathrm{~g}(+1.5 \mathrm{SD})$ and OFC $36 \mathrm{~cm}(+2 \mathrm{SD})$. She walked at $1 \frac{1}{2}$ years of age and was able to speak at $2 \frac{1}{2}$ years of age. She was referred to us at 6 years of age for overgrowth and psychomotor retardation. At this time, her height was $137 \mathrm{~cm} \mathrm{(+4} \mathrm{SD),} \mathrm{weight} \mathrm{was} 32.4 \mathrm{~kg}$ (+4 SD) and OFC was $61 \mathrm{~cm}$ (+5 SD). Dysmorphic features including a long triangular face with high forehead, downslanting palpebral fissures, small round and low set ears, a flat nasal bridge, and a normal palate were noted (Figure 2b). Clinical examination of the extremities showed clinodactyly of the fifth left finger and pes planus and valgus. Hyperlaxity and a lumbar lordosis were also noticed. She was mildly retarded and needed special education at school. $\mathrm{X}$-rays examination showed large epiphyses. Cardiac and renal ultrasound as well as neuroimaging showed no visceral malformations. Ophthalmologic examination showed a bilateral papillary coloboma. Endocrine studies including growth hormone and $17 \mathrm{OH}$ progesterone were normal. IGF1 concentration was $166 \mathrm{ng} / \mathrm{ml}$ (N: 126-260). Metabolic
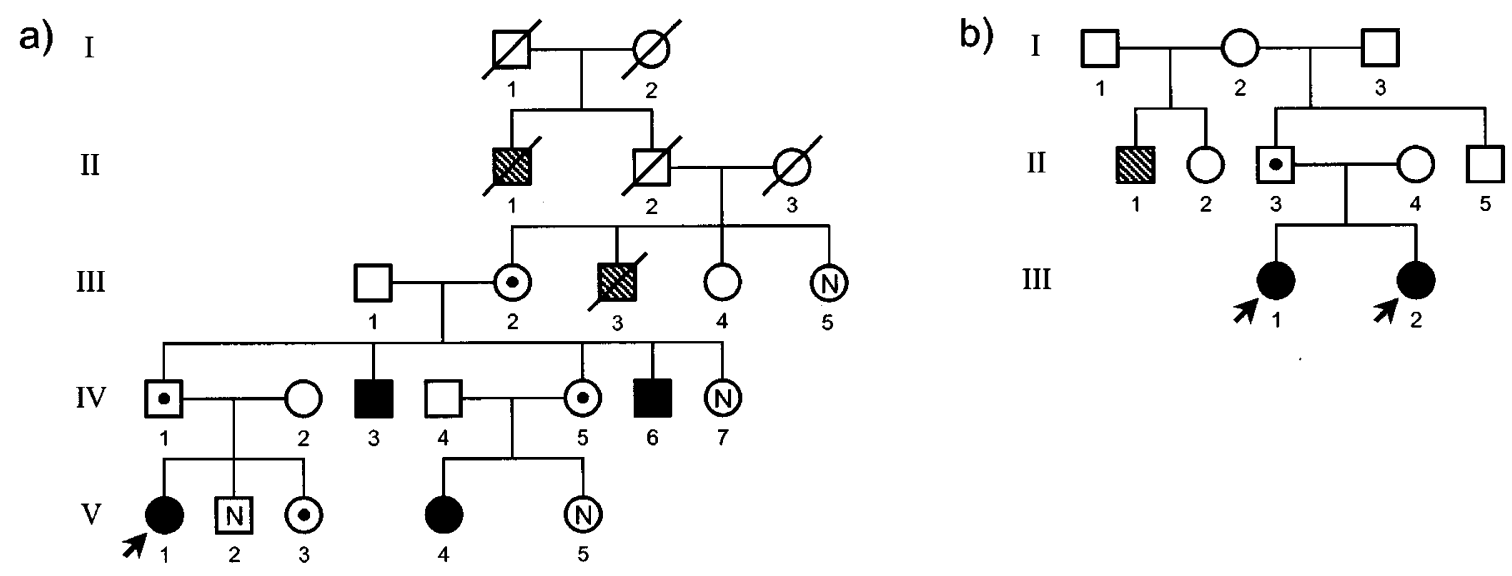

Figure 1 Pedigrees. (a) Family 1. (b) Family 2. Probands are shown by an arrow. Affected individuals are represented by black (unbalanced translocation) or hatched (not studied) symbols; $\mathrm{N}=$ normal karyotype; black dot: carriers of the translocation. 

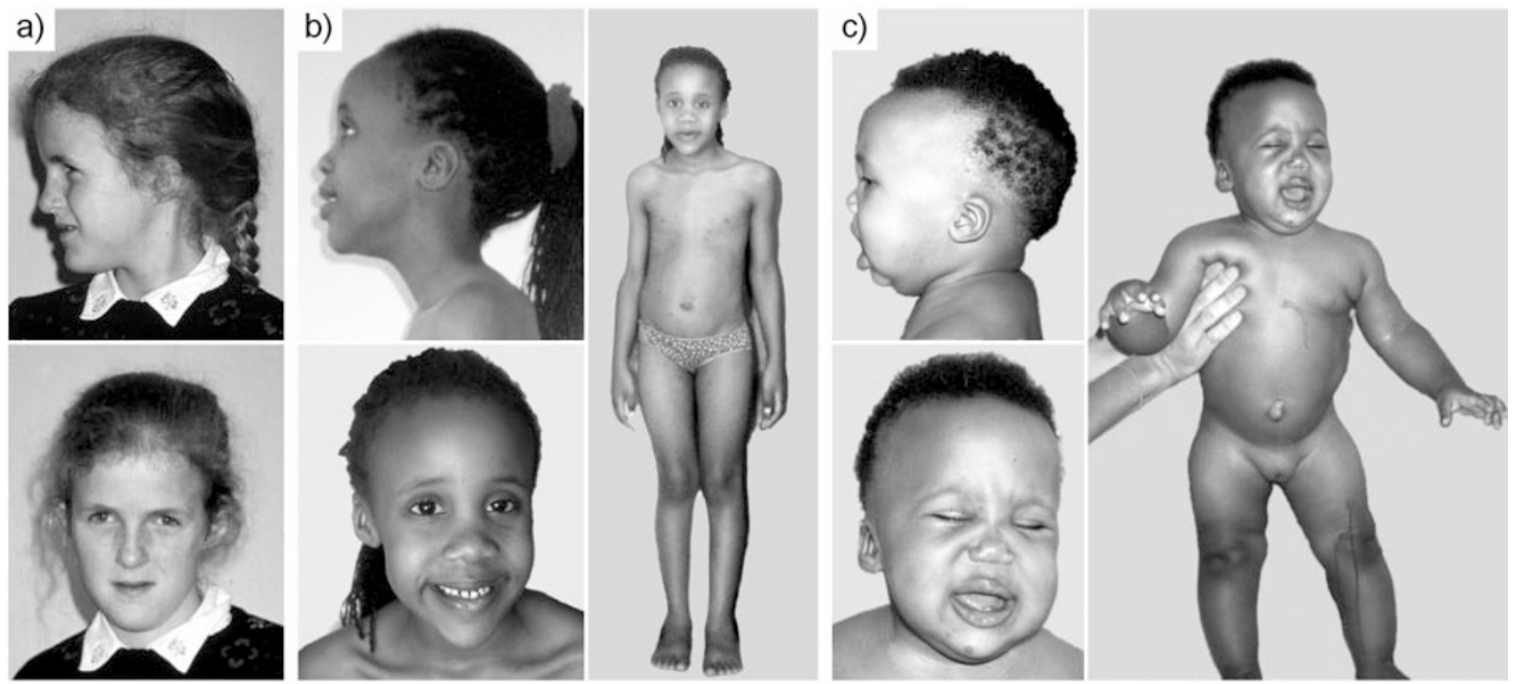

Figure 2 Photographs of the patients. (a) Patient (V-1) in family 1. (b) Older sib (III-1) of family 2 at age 6 years. (c) Her sister (III-2) at age 1 year. Note the long triangular face with high forehead and large chin.

studies including aminoacid and organic acid chromatography, isoelectric focusing of serum transferrin, very long chain fatty acids assay, mucopolysaccharides and oligosaccharides revealed normal results.

The second sibling was born at $37 \mathrm{WG}$ after an uneventful pregnancy. At birth, length was $52 \mathrm{~cm}(+2.5 \mathrm{SD})$, weight $4120 \mathrm{~g}(+4 \mathrm{SD})$ and OFC $39 \mathrm{~cm}(+5 \mathrm{SD})$. She was hypotonic and suffered neonatal distress due to a pneumothorax. She was referred to us at 11 months of age for overgrowth and psychomotor retardation. At this time, her length was $80 \mathrm{~cm}(+3.5 \mathrm{SD})$, weight was $13.6 \mathrm{~kg}(+4 \mathrm{SD})$ and OFC was $51 \mathrm{~cm}(+4 \mathrm{SD})$. Dysmorphic features included a long face with high forehead and a prominent metopic suture, epicanthal folds, small, round and low set ears, a very flat nose and nasal bridge, and a normal palate (Figure 2c). Hyperlaxity and clinodactyly of the fifth finger were noticed. She sat at 11 months of age. Ophthalmologic examination showed hypermetropia. Ultrasound cardiac scan showed ductus arteriosus. Cerebral imaging and renal ultrasound were normal. Similar endocrine and metabolic studies performed in her sister were normal.

\section{Cytogenetic and molecular studies}

Family 1 High resolution chromosome analysis using $\mathrm{R}$ and $\mathrm{G}$ banding techniques reveals a balanced translocation between chromosomes 15 and 20 in individual IV-5 (Figure 3a). Chromosome painting with whole chromosome painting WCP15 and WCP20 showed additional material originating from chromosome 15 on chromosome 20p, but no material originating from chromosome 20 on chromosome 15q (Figure 3b). FISH analysis with subtelomeric probes of chromosome 20p (PAC 82O2) and 15q (PAC 124O5) confirmed that the translocation was reciprocal (not shown). This suggest that the size of the translocated 20p segment is too small to be detected using chromosome painting. Comparative genomic hybridization $(\mathrm{CGH})^{10,11}$ was performed in $\mathrm{V}-1$ and confirmed the excess of material from 15q26.1-qter but did not show evidence of loss of 20p material (Figure 3d). Further FISH analyses with various probes of chromosome $15 q^{9,12-13,15}$ defined that the size of the $15 \mathrm{q}$ duplication ranged between 6 and $12 \mathrm{Mb}$ (Table 1). In particular, YAC 802B4 was not duplicated. The karyotype of IV-5 was therefore $46, \mathrm{XX}, \mathrm{t}(15 ; 20)(\mathrm{q} 26.1 ; \mathrm{p} 13)$. The same translocation was present in her healthy brother and in her mother. All affected patients are carriers of the same unbalanced karyotype with a $\operatorname{der}(20)$ resulting in trisomy 15q26.1-qter and a very subtle monosomy 20pter (Figure 3c).

Family 2 High-resolution chromosome analysis of the older sibling was performed on cultured peripheral blood lymphocytes using $\mathrm{R}$ and $\mathrm{G}$ banding techniques. These studies showed additional chromosome material of unknown origin on the long arm of chromosome 13 in all cells examined (Figure 4c). Fluorescence in situ hybridisation (FISH) analysis with a chromosome 15 painting probe was performed and confirmed that the additional material originated from chromosome 15 (Figure $4 \mathrm{~b}$ ). FISH analysis with subtelomeric probes of chromosome 13q (PAC 163C9) and 15q (PAC 124O5) showed one signal of chromosome $13 \mathrm{q}$ and three signals of chromosome $15 \mathrm{q}$ (not shown). CGH confirmed the excess of material from bands 15q26.1-qter, but did not show evidence of loss of 13q material (Figure 4d). Chromosome analysis of the parents showed that this unbalanced rearrangement resulted from the segregation of a paternal balanced trans- 
a)

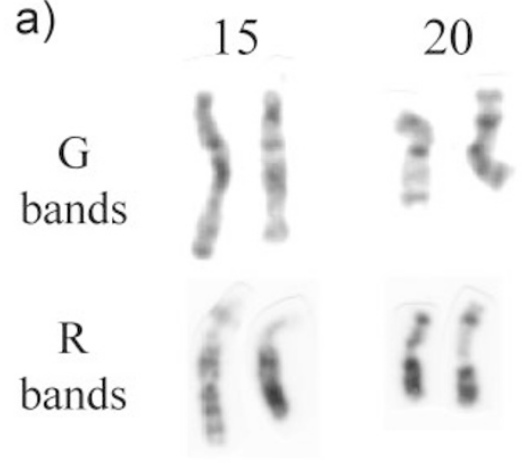

c)

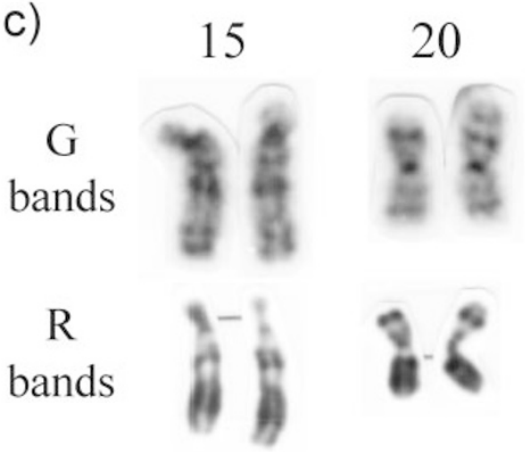

b)

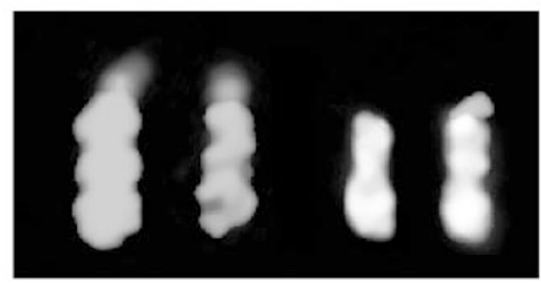

$15 \operatorname{der}(15) \quad 20 \operatorname{der}(20)$

d)

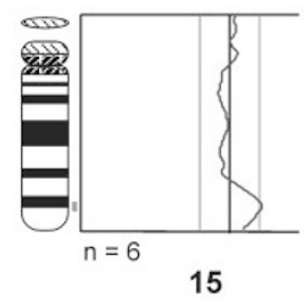

Figure 3 Family 1: chromosome analysis and FISH studies. (a) Balanced translocation $\mathrm{t}(15 ; 20)(\mathrm{q} 26.1 ; \mathrm{p} 13)$. Abnormal chromosomes are on the right. (b) Whole painting of chromosome 15 (grey) and 20 (white) of the balanced translocation. The small size of the translocated $20 p$ segment prevents its visualization. (c) Unbalanced translocation der(20)t(15;20). (d) CGH showing trisomy $15 q 26.1 \mathrm{qter}$. The monosomy $20 p$ is not detected.

Table 1 FISH characterisation of breakpoints of the two translocations

\begin{tabular}{|c|c|c|c|c|c|}
\hline Chromosomal location & Family 1 proband & Family 2 proband & Clone & Locus & Distance telomere ${ }^{a}$ \\
\hline $15 q 26.1$ & Disomy & Disomy & YAC CEPH-802B4 & D15S202 & $12 \mathrm{Mb}$ \\
\hline $15 q 26.2$ & Trisomy & Trisomy & YAC CEPH-895H 10 & D15S207 & $6 \mathrm{Mb}$ \\
\hline 15qter & Trisomy & Trisomy & PAC RP1-124O5 & WI-5214 & $300 \mathrm{~Kb}$ \\
\hline $13 q 34$ & Disomy & & YAC CEPH-908C3 & D13S261 & $3 \mathrm{Mb}$ \\
\hline $13 q 34$ & Disomy & & BAC RP11-65D24 & stSG47845 & $2.5 \mathrm{Mb}$ \\
\hline
\end{tabular}

${ }^{\mathrm{a} N C B I}$ built 28.

location. The same unbalanced karyotype was found in the younger sister. Further FISH analyses with various probes of chromosome $15 q^{12,13}$ defined that the size of the $15 q$ duplication ranged between 6 and $12 \mathrm{Mb}$ since YAC 802B 4 was not duplicated (Table 1). Similarly, we showed that the size of the $13 \mathrm{q}$ deletion was small, ranging from $80 \mathrm{~Kb}$ to $2.5 \mathrm{Mb}$. The karyotype of the father was therefore $46, X Y, t(13 ; 15)(q 34 ; q 26.1)$ (Figure 4a) and the children karyotypes were $46, \mathrm{XX}$, der(13)t(13;15)(q34;q26.1)pat.

\section{IGF1R gene}

FISH studies using an IGF1R probe (BAC 654A16) showed one signal on each $15 q$ and one on $20 p$ for proband $(\mathrm{V}-1)$ of family 1 (Figure 5a), and one signal on each $15 \mathrm{q}$ and one on $13 q$ for proband of family 2 (Figure $5 b$ ). Molecular studies using an intragenic polymorphic marker of the IGF1R gene performed in the proband of family 2 were fully informative. They showed three alleles of the IGF1R gene, two of which being of paternal origin (Figure $5 \mathrm{c}$ ) as 
a)

\section{G bands}

$\mathrm{R}$ bands

c)

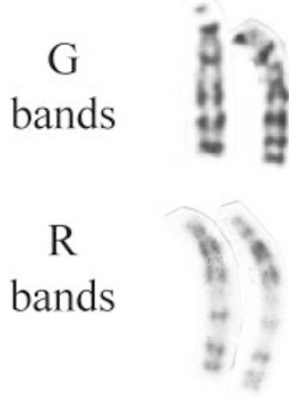

15

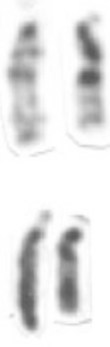

15

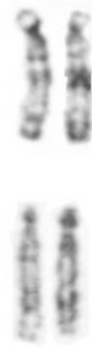

b)

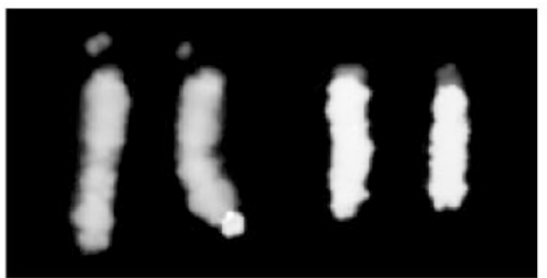

$13 \operatorname{der}(13) \quad 15 \operatorname{der}(15)$

d)
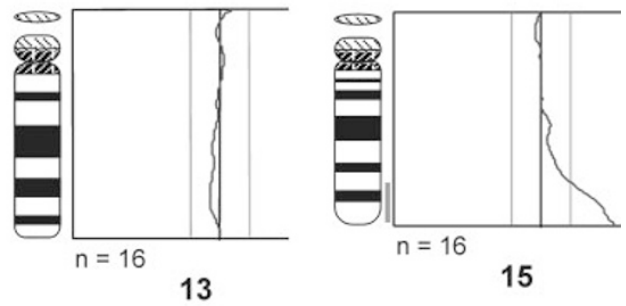

Figure 4 Family 2: chromosome analysis and FISH studies. (a) Balanced translocation $t(13 ; 15)(q 34 ; q 26.1)$. Abnormal chromosomes are on the right. (b) Whole painting of chromosome 13 (grey) and 15 (white) of the balanced translocation. The size of the translocated $13 q$ segment prevents its visualization. (c) Unbalanced translocation $\operatorname{der}(13) t(13 ; 15)$. (d) CGH showing trisomy 15q26.1qter. The monosomy $13 q$ is not detected.

expected. The polymorphic marker was identified from the published genomic sequence of IGF1R (http://genome.ucsc.edu/).

\section{Discussion}

Here, we report on two families with overgrowth and partial trisomy of chromosome 15q26.1-qter including the IGF1 receptor gene. In both cases, the associated monosomy is small in size.

The phenotype of distal trisomy $15 \mathrm{q}$, with a breakpoint being usually between $15 q 15$ and $15 q 22$, is well delineated. It includes mental retardation, growth deficiency, microdolichocephaly, peculiar facial features, skeletal abnormalities, and cardiovascular defects. ${ }^{14}$ Most of these cases result from the malsegregation of a parental translocation. In a few cases, the trisomy is confined to chromosome 15q25-qter and a different phenotype is observed, including macrosomia at birth, overgrowth, macrocephaly and craniosynostosis. $^{7}$ Also, mosaicism for an unstable interstitial duplication of chromosome band 15 q25 was recently described as a susceptibility factor for panic and phobic disorders. ${ }^{15}$ The segment duplicated on $15 \mathrm{q}$ in our patients is distal to this region as shown using YAC 802B4 which is located near its distal border.

Reports of six relevant patients with 15 q25 or 26 -qter trisomy and of the four present cases are summarised in Table $2 .^{16-18,7}$ Patients IV-3 et IV-6 of family 1 were not included because there was not enough of clinical data available. One report with cloverleaf skull anomaly was also excluded because of insufficient data. ${ }^{19}$ From this analysis, it appears that 8 out of 10 cases (six families) are familial. All cases result from an unbalanced segregation of a parental translocation with a breakpoint in 15 q25 or q26 and the breakpoint on the other chromosome located in the terminal band (except in one case). Interestingly, breakpoints found in our family 2 are similar to those found in the family reported by Zollino. ${ }^{7}$ Seven out of 10 cases presented with overgrowth between $+2 \mathrm{SD}$ and +6 DS. None of the patients presented with a size below the normal limit. Interfamilial variability in overgrowth is observed. There is also intrafamilial variability, as shown in our family 1 and the family reported by Zollino. ${ }^{7}$ The severity of overgrowth does not seem linked to the parental origin of the translocation. Indeed, overgrowth was noted in 3 out of 5 cases 
a)

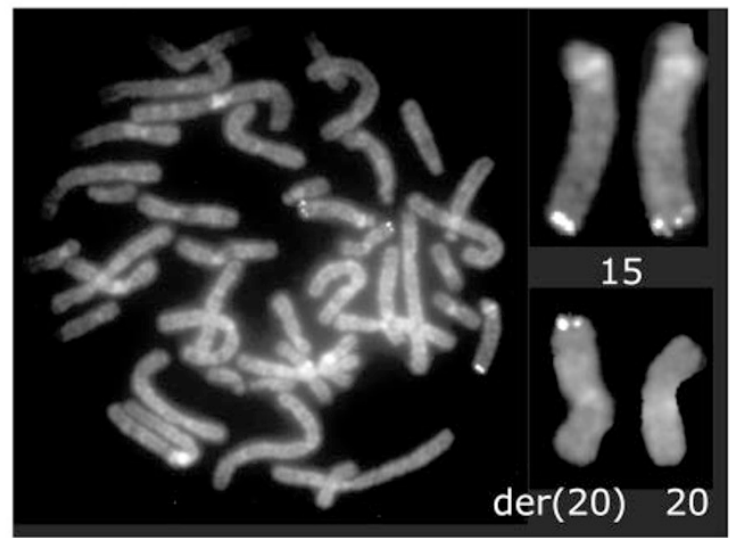

b)

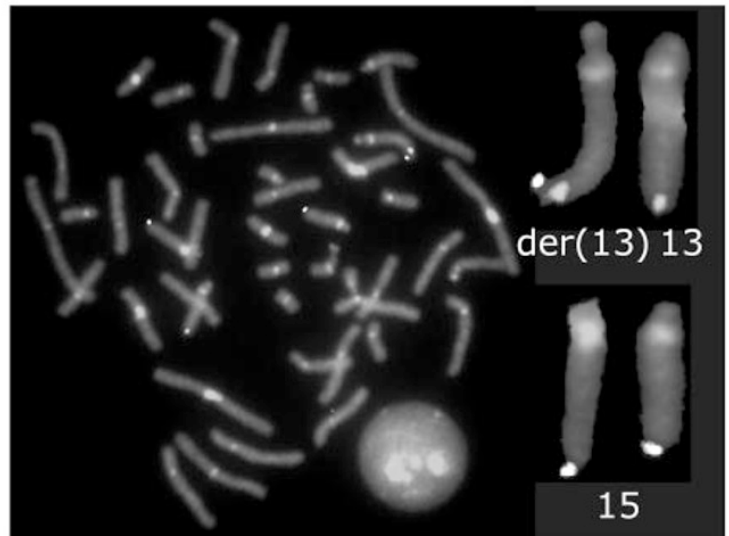

c)

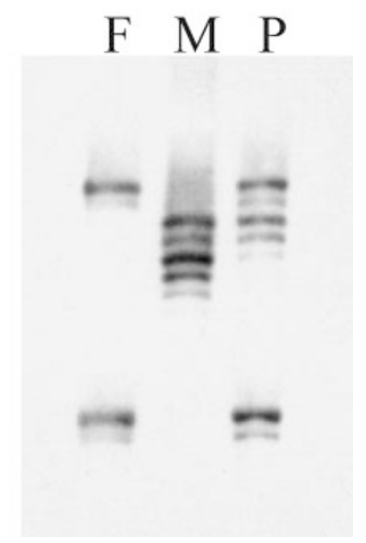

Figure 5 IGF1R: molecular and FISH studies. (a) FISH experiments with BAC 654A16 containing the IGF1R gene showed an additional signal at the end of the der(20) in proband of family 1. (b) FISH experiments with BAC 654A16 showed an additional signal at the end of the der(13) in proband of family 2. (c) Proband of family 2: an intragenic polymorphic microsatellite of the IGF1R gene (primers 5'-GAGTATGAACAGGTGGCATTAG-3' and 5'-ACATAGCCTTCATCCAACTTCC-3') showed three alleles of the gene of which two are of paternal origin. F: Father, M: Mother, P: Proband.

of paternal origin, and 4 out of 5 cases of maternal origin. Macrosomia was present at birth in 7 out of 8 informative patients, birth length ranging from 49 to $59 \mathrm{~cm}$ and weight from 3.3 to $5 \mathrm{~kg}$. If growth velocity seems to decelerate with age in some observations, ${ }^{7}$ tall stature is still present in adulthood in others. ${ }^{3}$ The adult size varies from 1.78 to $2.10 \mathrm{~m}$. Macrocephaly was even more frequent than overgrowth and was $\geqslant 4$ SD in 8 out of 10 cases. In one patient, macrocephaly is present without overgrowth. ${ }^{18}$ Craniosynostosis was associated in 3 out of 10 cases. Various cardiac defects or kidney malformations were found respectively in 3 out of 10 and 2 out of 9 cases, and scoliosis in 4 out of 10 cases. Psychomotor delay was a consistent feature and ranged from mild to severe. Distinctive facies found in most patients include a long and triangular face, downslanting palpebral fissures, and abnormal low-set ears. Finger abnormalities were often noted, such as arachnodactyly, flexed or tapering fingers.

It is well known that the insulin-like growth factors and their receptors are implicated in pre- and postnatal develop- ment. $^{20}$ The IGF1R is a transmembrane heterotetramer, which mediates the mitogenic effect of IGF1 and IGF2. Distal deletions of chromosome $15 \mathrm{q}$ are associated with severe growth retardation. ${ }^{9,21-24}$ It has been suggested that growth failure might be related to IGF1R hemizygosity. On the contrary, in the present observations, overgrowth might well be related to a dosage excess of IGF1R gene.

Also, a gene for macrocephaly is likely to be located in this region. Interestingly a large family with autosomal recessive syndrome of macrocephaly, multiple epiphyseal dysplasia and distinctive facies was recently reported and a gene locus was identified in $15 q 26 .{ }^{24}$ The aggrecan gene (AGC1), a chondroitin sulphate proteoglycan that was a possible candidate gene, was excluded. ${ }^{25}$

In conclusion, we report on four further cases of overgrowth associated with trisomy 15q26.1-qter including the IGF1R locus. The present report gives further evidence for a specific phenotype related to trisomy $15 q 25$ or 26-qter with macrosomia at birth, overgrowth, macrocephaly and mild developmental delay being the major clinical features. 
Table 2 Clinical findings in 10 patients with $15 q 25$ or 26 -qter trisomy

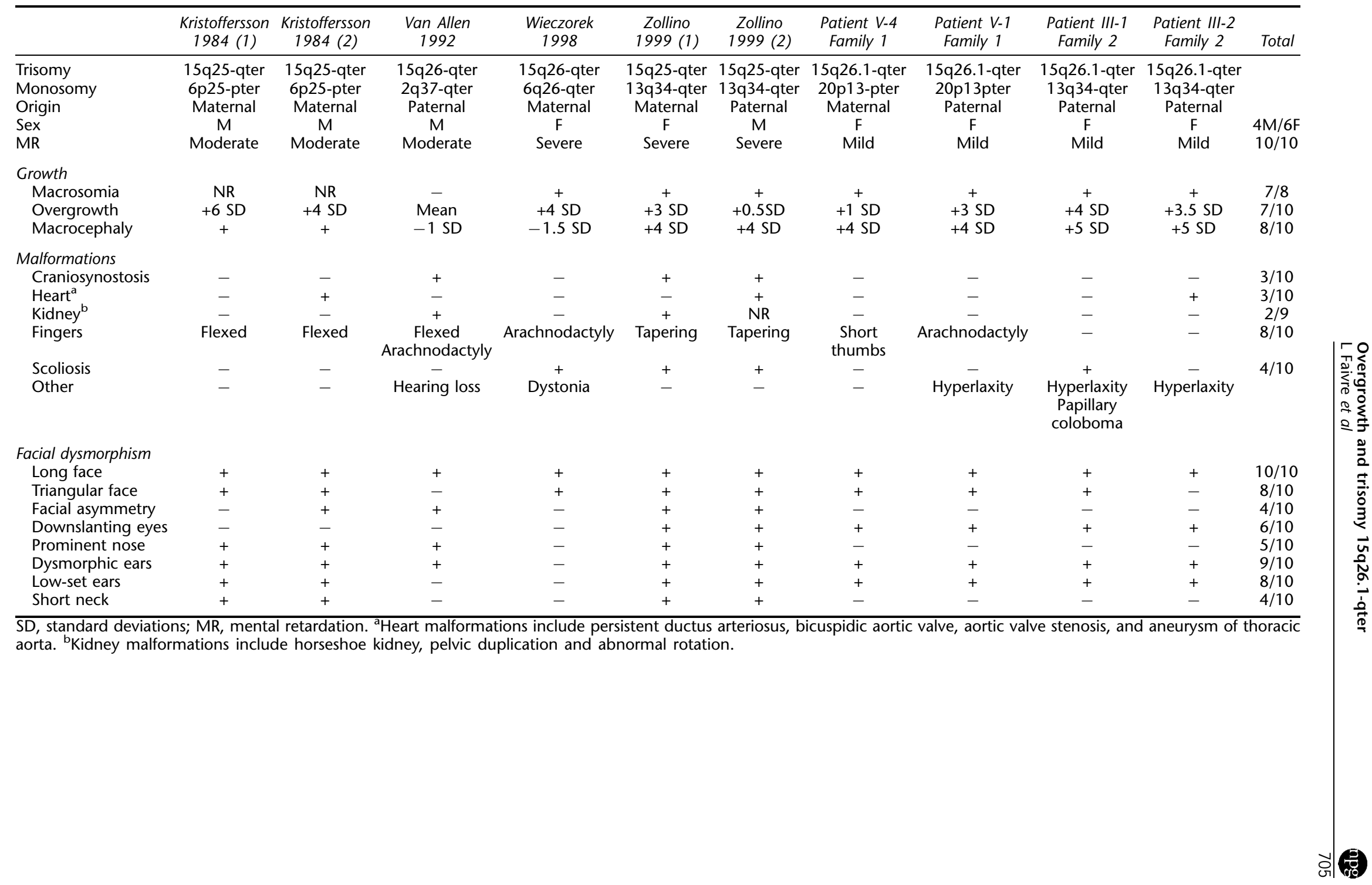


We suggest that overgrowth might be causally related to a dosage excess of IGF1R gene. Interestingly, overgrowth has also been reported in patients with tetrasomy of chromosome $15 \mathrm{q} 25$-qter, ${ }^{8}$ as well as in some patients with larger trisomy $15 q 22$ qter. $^{26,27}$ Mainly, this report emphasizes the importance of chromosome analysis in the investigation of patients with overgrowth and mental retardation. Further studies of similar cases will provide a valuable opportunity for elucidating the molecular basis of overgrowth.

\section{Acknowledgements}

We thank $\operatorname{Pr} B$ Le Marec for his clinical expertise and help with family 1. M Picq, C Ozilou and JM Lapierre are acknowledged for their excellent technical work and Y Deris for his photographic assistance.

\section{References}

$1 \mathrm{Li} \mathrm{M}$, Squire JA, Weksberg R: Molecular genetics of WiedemannBeckwith syndrome. Am J Med Genet 1998; 79: 253-259.

2 Neri G, Gurrieri F, Zanni G, Lin A: Clinical and molecular aspects of the Simpson-Golabi-Behmel syndrome. Am J Med Genet 1998; 79: $279-283$.

3 Kurotaki N, Imaizumi K, Harada N et al: Haploinsufficiency of NSD1 causes Sotos syndrome. Nat Genet 2002; 30: 365-366.

4 Partington MW, Fagan K, Soubjaki V, Turner G: Translocations involving 4p16.3 in three families: deletion causing the PittRogers-Danks syndrome and duplication resulting in a new overgrowth syndrome. J Med Genet 1997; 34: 719-728.

5 Elliott M, Maher ER: Syndrome of the month: Beckwith-Wiedemann syndrome. J Med Genet 1994; 31: 560-564.

6 Faivre L, Viot G, Prieur M et al: Apparent Sotos syndrome (cerebral gigantism) in a child with trisomy 20p11.2-p12.1 mosaicism. Am J Med Genet 2000; 91: 273-276.

7 Zollino M, Tiziano F, Di Stefano C, Neri G: Partial duplication of the long arm of chromosome 15: Confirmation of a causative role in craniosynostosis and definition of a 15q25-qter trisomy syndrome. Am J Med Genet 1999; 87: 391-394.

8 Rowe AG, Abrams L, Qu Y, Chen E, Cotter PD: Tetrasomy $15 q 25 \rightarrow$ qter: Cytogenetic and molecular characterization of an analphoid supernumerary marker chromosome. Am J Med Genet 2000; 93: 393-398.

9 Peoples R, Milatovich A, Francke U: Hemizygosity at the insulinlike growth factor I receptor (IGF1R) locus and growth failure in the ring chromosome 15 syndrome. Cytogenet Cell Genet 1995; 70: $228-234$.

10 Kallioniemi A, Kallioniemi OP, Sudar D, Rutovitz D, Gray JW, Waldman F, Pinkel D: Comparative genomic hybridization for molecular cytogenetic analysis of solid tumors. Science 1992; 258: 818-821.

11 Lapierre JM, Cacheux V, Da Silva F, Collot N, Hervy N, Wiss J, Tachdjian G: Comparative genomic hybridization: technical development and cytogenetic aspects for routine use in clinical laboratories. Ann Genet 1998; 41: 56-62.
12 Kingsley K, Wirth J, van der Maarel S, Freier S, Ropers HH, Haaf T: Complex FISH probes for the subtelomeric regions of all human chromosomes: comparative hybridization of CEPH YACs to chromosomes of the Old World monkey Presbytis cristata and great apes. Cytogenet Cell Genet 1997; 78: 12-19.

13 Knight SJ, Lese CM, Precht KS et al: An optimized set of human telomere clones for studying telomere integrity and architecture. Am J Hum Genet 2000; 67: 320-332.

14 Chandler K, Schrander-Strumpel CTRM, Engelen J, Theunissen P, Fryns JP: Partial trisomy 15q: report of a patient and literature review. Genet Couns 1997; 8: 91-97.

15 Gratacos M, Nadal M, Martin-Santos R et al: A polymorphic genomic duplication on human chromosome 15 is a susceptibility factor for panic and phobic disorders. Cell 2001; 106: $367-379$.

16 Kristoffersson ULF, Bergwall B: Partial trisomy 15(q25qter) in two brothers. Hereditas 1984; 100: 7-10.

17 Van Allen MI, Siegel-Bartelt J, Feigenbaum A, Teshima IE: Craniosynostosis associated with partial duplication of $15 \mathrm{q}$ and deletion 2q. Am J Med Genet 1992; 43: 688-692.

18 Wieczorek D, Engels H, Viersbach R, Henke B, Schwanitz G, Passarge E: Analysis of a familial three way translocation involving chromosomes $3 \mathrm{q}, 6 \mathrm{q}$, and $15 \mathrm{q}$ by high resolution banding and fluorescent in situ hybridisation (FISH) shows to different unbalanced karyotypes in sibs. J Med Genet 1998; 35: 545-553.

19 Pedersen C: Partial trisomy 15 as a result of an unbalanced 12/15 translocation in a patient with a cloverleaf skull anomaly. Clin Genet 1976; 9: 378-380.

20 Baker J, Lui JP, Robertson EJ, Efstratiadis A: Role of insulin-like growth factors in embryonic and postnatal growth. Cell 1993; 75: $73-82$.

21 de Lacerda L, Carvalho JA, Stannard B et al: In vitro and in vivo responses to short-term recombinant human insulin-like growth factor-1 (IGF-1) in a severely growth-retarded girl with a ring chromosome 15 and deletion of a single allele for the type I IGF receptor gene. Clin Endocrinol 1999; 51: 541-550.

22 Siebler T, Lopaczynski W, Terry CL et al: Insulin-like growth factor I receptor expression and function in fibroblasts from two patients with deletion of the distal long arm of chromosome 15. J. Clin Endocrinol Metab 1995; 80: 3447 - 3357.

23 Tamura T, Tohma T, Ohta T et al: Ring chromosome 15 involving deletion of the insulin-like growth factor 1 receptor gene in a patient with features of Silver-Russell syndrome. Clin Dysmorphol 1993; 2: 106-113.

24 Roback EW, Barakat AJ, Dev VJ, Mbikay M, Chrétien M, Butler MG: An infant with deletion of the distal long arm of chromosome $15(\mathrm{q} 26.1 \rightarrow \mathrm{qter})$ and loss of insulin-like growth factor 1 receptor gene. Am J Med Genet 1991; 38: 74-79.

25 Bayoumi R, Saar K, Lee YA et al: Localisation of a gene for an autosomal recessive syndrome of macrocephaly, multiple epiphyseal dysplasia, and distinctive facies to chromosome 15q26. J Med Genet 2001; 38: 369-373.

26 Gregoire MJ, Boue J, Junien C, Pernot C, Gilgenkrantz S, Zergollern L: Duplication of $15 \mathrm{q} 22 \rightarrow 15 \mathrm{qter}$ and its phenotypic expression. Hum Genet 1981; 59: 429-433.

27 Goldstein DJ, Ward RE, Nichols WC, Palmer CG: Familial $\mathrm{t}(8 ; 15)(\mathrm{p} 23.3 ; \mathrm{q} 22.3)$ : report of two cases with dup(15)(q22.3 $\rightarrow$ qter). J Med Genet 1987; 24: 684-687. 